\title{
RESVERATROL YÜKLÜ SELÜLOZ ASETAT LİFLERİNİN KARAKTERİZASYONU
}

\author{
Fahriye Ceyda Dudak \\ Hacettepe Üniversitesi, Mühendislik Fakültesi, Gıda Mühendisliği Bölümü, Ankara, Türkiye
}

Geliş / Received: 01.07.2019; Kabul / Accepted: 23.07.2019; Online bask1 / Published online: 23.08.2019

Dudak, F. C. (2019). Resveratrol yüklü selüloz asetat liflerinin karakterizasyonu. GIDA (2019) 44 (5): 810-818 doi: 10.15237/gida.GD19098

Dudak, F. C. (2019). Characterization of resveratrol loaded cellulose acetate fibers. GIDA (2019) 44 (5): 810-818 doi: $10.15237 /$ gida.GD19098

\section{ÖZ}

Bu çalışmada, selüloz asetat çözeltisinden elektroeğirme prosesi ile enkapsülasyon matrisleri üretilmiş ve bu matrislerin resveratrolün enkapsülasyonundaki performansları incelenmiştir. Taramalı elektron mikroskobu (SEM) ile incelendiğinde, selüloz asetat liflerinin düzgün yüzeyli olduğu ve damlacik içermediği görülmüştür. Resveratrol yüklü liflerin ve yüksüz liflerin ortalama çapları sırasıyla $493 \mathrm{~nm}$ ve $478 \mathrm{~nm}$ olarak belirlenmiştir. Resveratrolün enkapsülasyon etkinliği \%94.5 olarak bulunmuştur. Antioksidan aktivite analizi, depolama sırasında elektroeğrilmiş liflere enkapsülasyon ile biyoaktif bileşiğin bozunmasının azaldı̆̆ını ortaya koymuştur. In vitro salınım çalsşması, 20 saat içerisinde başlangç̧taki resveratrolün \%11'inin tampon ortamına salındığını ve sonrasında salınımın durduğunu göstermiştir. Sonuç olarak, elektroeğrilmiş selüloz asetat liflerinin resveratrol için etkin enkapsülasyon matrisleri olarak kullanılma potansiyeli olduğu belirlenmiştir.

Anahtar kelimeler: Resveratrol, selüloz asetat, elektroeğirme, lif, enkapsülasyon

\section{CHARACTERIZATION OF RESVERATROL LOADED CELLULOSE ACETATE FIBERS}

\begin{abstract}
In this work, encapsulation matrices were fabricated by electrospinning of cellulose acetate solution and their performance for the encapsulation of resveratrol was evaluated. Scanning electron microscopy (SEM) results showed that cellulose acetate fibers were bead-free and smooth. The mean diameters of resveratrol loaded and unloaded fibers were found to be $493 \mathrm{~nm}$ and $478 \mathrm{~nm}$, respectively. Encapsulation efficiency of resveratrol was 95\%. Antioxidant activity assay confirmed that the encapsulation via electrospun fibers reduced the degradation of bioactive compounds during storage. In-vitro release study showed that $11 \%$ of the resveratrol in cellulose acetate fibers was released into buffer medium within $20 \mathrm{~h}$ and after that, the release reached plateau. Therefore, electrospun cellulose acetate fibers are promising to be used as an efficient encapsulating matrices for resveratrol.
\end{abstract}

Keywords: Resveratrol, cellulose acetate, electrospinning, fiber, encapsulation

\footnotetext{
* Yazışmalardan sorumlu yazar / Corresponding author;

凶 ceyda@hacettepe.edu.tr, @ (+90) 3122977103 岛 (+90) 3122992123
} 


\section{GİRIŞ}

Biyoaktif gıda bileşenlerinin bazı hastalıkların önlenmesi veya tedavi edilmesinde etkili olduğu ortaya konmuştur. Bunlar arasinda, resveratrol (3,5,4'-trihidroksi-trans-stilben) antioksidan, antikanserojen, antiinflamatuar ve antiviral etkilerinden dolayı oldukça ilgi görmektedir (Rauf vd., 2017). Resveratrol yer fistığ1, üzüm, erik ve kırmızı şarap gibi birçok gıdada bulunan doğal bir polifenolik bileşiktir (Penalva vd., 2015). Son yıllarda yapilan çalışmalar sonucunda resveratrolün düşük yoğunluklu lipoprotein (LDL) peroksidasyonunu engellediği, ventriküler aritmiyi azalttığı, kan basıncını düşürdüğü, trombosit agregasyonunu ve çözünür adhezyon moleküllerinin oluşumunu engelleyerek kardiyovasküler hastalıkların önlenmesinde yardımcı olabileceği ortaya konmuştur (Orallo vd., 2002). Buna ek olarak, resveratrolün diyabete karşı koruyucu etkisi ve obezitenin tedavisinde etkili bir rol alabileceği gösterilmiştir (Palsamy ve Subramanian, 2011; Alves vd., 2012; Timmers vd., 2011). Sağlık üzerindeki tüm bu olumlu etkilerin sonucu olarak resveratrolün gidalara katılmas gündeme gelmiştir. Ancak, bu koşullarda düşük çözünürlüğü, kimyasal kararsızlığ1 ve hızlı metabolize olması nedeniyle resveratrolün in-vivo etkinliği azalmaktadır (Riccitiello vd., 2018). Bu nedenle, resveratrolün in-vitro koşullarda stabilitesinin arttırlmasi ve oral tüketimi sonrasında biyoyararlılı̆̆ının iyileştirilmesi amaciyla enkapsülasyon sistemlerinin geliştirilmesi önemlidir.

$\mathrm{Bu}$ çalışmada, resveratrolün elektroeğirme yöntemi ile liflerin içerisine enkapsülasyonu amaçlanmıştır. Elektroeğirme yöntemi farklı polimerlerin kullanılabildiği, mikrometre ve nanometre ölçekte liflerin üretiminde etkin bir teknik olarak karşımıza çıkmaktadır (Ghorani ve Tucker, 2015). Son yllarda, bu teknik biyoaktif bileşiklerin liflere enkapsülasyonunda da siklikla kullanılmaya başlanmıştır (Aceituno-Medina vd., 2015). Elektroeğrilmiş liflerin yüksek yüzey-hacim oranına sahip olması, porlu yapıda olmaları, düşük sıcaklıkta üretimlerinin mümkün olması ve farklı polimer karışımlarının kullanımına imkan tanıması sayesinde her geçen gün kullanım alanı artmaktadır (Aytac vd., 2017). Birçok farklı biyoaktif bileşikte olduğu gibi, elektroeğirme yöntemi resveratrolün enkapsülasyonu için başarılı bir şekilde kullanılmıştır. Resveratrol yüklü polikaprolakton ve polilaktik asit polimerlerinden elde edilen lifler ile resveratrolün kontrollü salınımı gerçekleştirilmiş ve osteoblast üzerine etkileri incelenmiştir (Riccitiello vd., 2018). Resveratrol içeren polikaprolakton liflerin periyodontal hastalıklarin tedavisinde de kullanılabileceği gösterilmiştir (Zupančič vd., 2015). Başka bir çalışmada, yara pansuman malzemesi olarak kitosan ve polikaprolakton koaksiyel elektroeğrilmiş nanolifler ile ferulik asit ve resveratrolün enkapsülasyonu gerçekleştirilmiş ve salınım özellikleri incelenmiștir (Poornima ve Korrapati, 2017). Benzer şekilde, polikaprolakton ve jelatin ile oluşturulan koaksiyel lifler ile resveratrolün lokal salınımı amaçlanmış ve lösemi hücreleri üzerindeki terapötik etkileri araştırllmıştır (Al-Attar ve Madihally, 2018). Ancak yapılan bu çalışmalarda, resveratrol için tasarlanan taşıyıcı sistemler farklı hastalıkların tedavisi için geliştirilmiştir. Taşıyıcı sistemlerin gıdalarda kullanımı söz konusu olduğunda enkapsülasyon materyalinin gidalarda kullanılabilir ve genellikle güvenilir kabul edilen (generally recognized as safe) sinifta olmasi, üretiminin ucuz olmas1, g1da ürününün görünüşü, yapıs1, tadı ve kokusu üzerinde olumsuz etkisi olmamasi ve gidanin depolanmasi sirasinda stabilitesini koruması gibi ek gereksinimlere ihtiyaç duyulmaktadır (Davidov-Pardo ve McClements, 2014). Elektroeğirme yöntemi ile enkapsülasyonda sıklıkla kullanılan polimerlerden biri olan selüloz asetat toksik olmaması, yüksek 1s1 ve mekanik stabiliteye sahip olması, biyoçözünür olması ve kimyasal dirence sahip olması gibi avantajlar1 sayesinde bu gereksinimleri büyük oranda karşılamaktadır (Han vd., 2008). Elektroeğrilmiş selüloz asetat lifleri Acanthus ebracteatus V abl. ekstrakt1, 6-gingerol, kurkumin ve asiatikosit gibi farklı biyoaktif bileşiklerin enkapsülasyonunda başarıyla kullanılmıştır (Vongsetskul vd., 2016; Chantarodsakun vd., 2014; Suwantong vd., 2007; Suwantong vd., 2008).

Bu çalışmada, literatürde ilk defa resveratrol ilave edilmiş selüloz asetat polimeri kullanılarak 
elektroeğirme yöntemi ile lifler elde edilmiş ve geliştirilen taşı1c1 sistemin biyoaktif bileşik enkapsülasyonu için performansı incelenmiştir. Çalışma kapsamında lifler taramalı elektron mikroskobu (SEM, scanning electron microscope) ve Fourier dönüşümlü kızılötesi (FTIR, Fourier transform infrared) spektroskopisi ile karakterize edilmiştir. Resveratrol yüklü liflerin zamana ve sıcaklığa bağlı antioksidan aktiviteleri 2,2-difenil-1-pikrilhidrazil (DPPH) analizi ile belirlenmiştir. Ayrıca, tampon çözelti içerisinde elektroeğrilmiş liflerden resveratrolün salınımı incelenmiștir.

\section{MATERYAL VE YÖNTEM \\ Materyal}

Selüloz asetat (moleküler ağırlı̆̆1 $30000 \mathrm{Da}$ ), asetik asit (99.8-100\%), etanol (saflık, $\geq 99.8 \%$ ), potasyum fosfat monobazik, sodium fosfat dibazik heptahidrat ve 2,2-difenil-1-pikrilhidrazil (DPPH) Sigma-Aldrich (St. Louis, MO, USA) firmasından temin edilmiştir. Trans-resveratrol $\left(\operatorname{ResVida}^{\circledR}\right)$ DSM Nutritional Products Ltd. (Kaiseraugust, Switzerland) firmasindan alınmıştır.

\section{Elektroeğirme Prosesi}

Elektroeğirme prosesi için \%15 (a/a) selüloz asetat çözeltisi asetik asit:etanol (8:2, h/h) içerisinde hazırlanmışır. Resveratrol stok çözeltisi $50 \mathrm{mg} / \mathrm{mL}$ derişimde etanol içerisinde hazırlanmış ve polimerin ağırlıkça \%1.5'i olacak şekilde çözeltiye ilave edilmiştir.

Elektroeğirme prosesi yüksek voltaj güç kaynağına ve dönen kollektöre sahip Electrospinning ESM 1100 (Solvan A.Ş., Ankara, Türkiye) cihazı ile gerçekleştirilmiştir. Resveratrol içermeyen ve resveratrol yüklü selüloz asetat çözeltileri $21 \mathrm{G}$ başlıklı plastik şırıngalara yüklenmiş ve şırıngalar dijital kontrollü şırınga pompasina (New Era NE-1000, Scientific Instrument Services, Ringoes, NJ, ABD) yerleştirilmiştir. Çözeltiler $35 \mathrm{kV}$ potansiyelde, uçkollektör mesafesi $10 \mathrm{~cm}$ olacak şekilde, 3 $\mathrm{mL} / \mathrm{saat}$ akış hızında beslenmiştir. Yüklü ve yüksüz lifler aynı işlem parametreleri ile üretilmiştir.

\section{Elektroeğrilmiş liflerin karakterizasyonu}

Resveratrol, selüloz asetat lifleri ve resveratrol yüklü selüloz asetat liflerinin kimyasal yapısı tekli elmas kristal ve triglisin sülfat dedektöre sahip Fourier dönüşümlü kızılötesi (FTIR) spektroskopisi (Thermo Nicolet IS50, Thermo Fisher Scientific Co., Waltham, MA, ABD) ile analiz edilmiştir. Ölçümler için 4000-400 $\mathrm{cm}^{-1}$ dalga sayısı aralı̆̆ında, $4 \mathrm{~cm}^{-1}$ çözünürlükte 32 taramanın ortalaması alınarak kızılötesi spektrumları elde edilmiştir.

Elektroeğrilmiş liflerin morfolojileri ve çapları emisyon taramalı electron mikroskobu (ESEM) (FEI-Quanta 200 FEG, Thermo Fisher Scientific Co., Waltham, MA, ABD) ile belirlenmiştir. Bunun için örnekler püskürtmeli kaplama cihazı (Precision Etching and Coating System (PECS) 682, Gatan Inc., Pleasanton, CA, USA) kullanılarak ince altın-paladyum tabakası ile kaplanmıştır. Örneklerin ESEM görüntüleri 5000x yakınlaştırma ile elde edilmiştir. Ortalama lif çapları ve çap histogramları ImageJ yazılımı (NIH, Maryland, ABD) ile hesaplanmıştır.

\section{Enkapsülasyon etkinliği}

Liflerin enkapsülasyon etkinliğinin belirlenmesi için resveratrol yüklü liflerden $1 \mathrm{mg}$ alınarak $5 \mathrm{~mL}$ $0.05 \mathrm{M}$ fosfat tampon çözeltisi ( $\mathrm{pH}$ 7.4) ile karıştırılmış ve oda sıcakliğında 30 saniye boyunca karıştırılmıştır. Daha sonra çözeltiler 10000 xg'de 5 dakika santrifüjlenmiş ve supernetantın absorbans değeri $310 \mathrm{~nm}$ dalgaboyunda Agilent 8453 UV-Visible spektrofotometresi (Agilent Technologies, Santa Clara, CA, ABD) ile ölçülmüştür. Supernetanta geçen resveratrol miktarı standart kalibrasyon eğrisinden bulunmuştur. Enkapsülasyon etkinliği (\%EE) Eşitlik 1'e göre hesaplanmıştır:

$\% \mathrm{EE}=[($ Teorik toplam resveratrol konsantrasyonu-enkapsüle olmayan resveratrol konsantrasyonu) / teorik toplam resveratrol konsantrasyonu $] \times 100$

\section{Resveratrolün salınımının incelenmesi}

Resveratrol yüklü selüloz asetat liflerden alınan 10 $\mathrm{mg}, 500 \mu \mathrm{L} 0.05 \mathrm{M}$ fosfat tampon çözeltisi $(\mathrm{pH}$ 7.4) içerisine alınmış ve oda sicaklığında orbital karıştırıcıda inkübe edilmiştir. İnkübasyon 
başlangıcından itibaren 1., 2., 4., 8., 16., 20., 22., ve 24. saatlerde tampon çözeltiden örnek alınarak $310 \mathrm{~nm}$ dalgaboyunda spektrofotometre ile salınan resveratrol miktarı belirlenmiştir.

\section{Antioksidan aktivite}

Örneklerde antioksidan aktivite analizi DPPH analizi ile gerçekleştirilmiştir (Serpen vd., 2007). Resveratrol yüklü lifler $4^{\circ} \mathrm{C}$ ve $25^{\circ} \mathrm{C}$ olmak üzere iki farklı sıcaklıkta depolanmış ve belirli zaman araliklarından liflerden $10 \mathrm{mg}$ alınarak $100 \mu \mathrm{L}$ asetik asit içerisinde çözünmesi sağlanmıştır. Elde edilen bu çözeltiye $10 \mathrm{~mL}$ DPPH çözeltisi ilave edilmiş ve 1 saat boyunca orbital çalkalayıcıda karıştırılmıştır. İnkübasyon sonunda çözeltiler $10000 \times$ g'de 5 dakika santrifüj edilmiş ve supernatantların absorbans değerleri $310 \mathrm{~nm}$ dalgaboyunda spektrofotometre ile ölçülmüştür. Negatif kontrol olarak resveratrol yüklenmemiş liflere de aynı işlem uygulanmıstır. Enkapsüle resveratrol ile karşılaştırmak amacıyla serbest resveratrolün antioksidan aktivitesi de incelenmiştir. Örneklere ait antioksidan aktivite Eşitlik 2'ye göre hesaplanmıştır. Eşitlikte $A_{\text {kontrol lif içermeyen DPPH çözeltisinin }}$ absorbans değerini, $A_{\text {örnek }}$ ise lif içeren reaksiyon ortamının absorbans değerini ifade etmektedir.

$\%$ antioksidan aktivite $=\left[\left(\mathrm{A}_{\text {kontrol }}-\mathrm{A}_{\text {örnek }}\right) / \mathrm{A}_{\text {kontrol }}\right]$ $\times 100$

\section{SONUÇLAR VE TARTIŞMA}

\section{Elektroeğrilmiş liflerin karakterizasyonu}

Resveratrolün, yüksüz selüloz asetat liflerinin ve resveratrol yüklü liflerin ATR-FTIR spektrumları
Şekil 1'de görülmektedir. Selüloz asetat spektrumunda $\mathrm{C}=\mathrm{O}$ esnemesi ile ilgili $1735 \mathrm{~cm}^{-1}$ ve C-H eğilmesi ile ilgili $1366 \mathrm{~cm}^{-1}$ dalga sayısında karakteristik pikler görülmektedir. Bunun yaninda, $1214 \mathrm{~cm}^{-1}$ ve $1030 \mathrm{~cm}^{-1}$ dalga sayısinda görülen pikler ise $\mathrm{C}-\mathrm{O}$ esnemesi ile ilişkilendirilmektedir (Keun vd., 2004). Resveratrole ait karakteristik parmak izi bölgesi 600 ile $1630 \mathrm{~cm}^{-1}$ arasında görülmektedir. Resveratrolün spektrumunda $1605 \mathrm{~cm}^{-1}, 1583 \mathrm{~cm}^{-}$ 1 ve $1380 \mathrm{~cm}^{-1}$ dalga sayısında görülen pikler sirasiyla, C-C aromatik çift bağ esnemesi, C-C olefinik esnemesi ve C-C esnemesiyle ilişkilendirilmekte ve $964 \mathrm{~cm}^{-1}$ dalga sayısında görülen pik ise resveratrolün trans formundan kaynaklanmaktadır (Kumpugdee-Vollrath vd., 2012). Resveratrol yüklü selüloz asetat liflerine ait spektrum yüksüz liflere ait spektrumla büyük oranda benzerlik göstermekle birlikte, yüksüz liflerden farkli olarak $1605 \mathrm{~cm}^{-1}, 1514 \mathrm{~cm}^{-1}$ ve 830 $\mathrm{cm}^{-1}$ dalga sayısinda görülen pikler resveratrol varllğını işaret etmektedir. Resveratrol içeren liflere ait spektrumda yeni oluşan bir pik veya pik dalga sayılarında önemli bir kayma görülmemesi resveratrolün selüloz asetat içerisinde sadece fiziksel olarak tutunduğunu düşündürmektedir. Resveratrol ve polimer arasinda herhangi bir kimyasal bağın oluşmamasının, biyoaktif bileşiğin salınımını kolaylaştıracağı ve tüketim sonrasında da aktivitesinde önemli bir değişikliğe yol açmayarak biyoyararlılığını arttırabileceği düşünülmektedir.

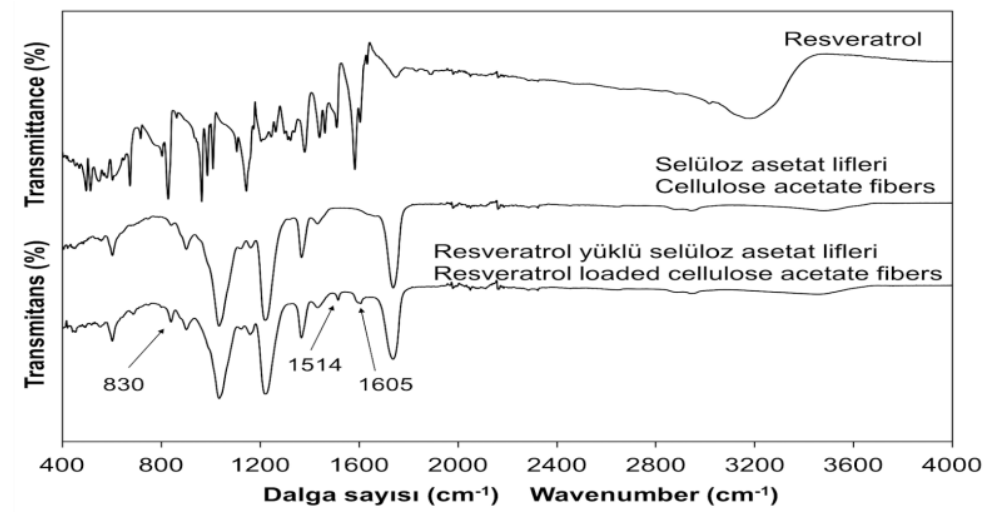

Şekil 1. Resveratrole, selüloz asetat liflerine ve resveratrol yüklü selüloz asetat liflerine ait ATR-FTIR spektrumlar1

Figure 1. ATR-FTIR spectra of resveratrol, cellulose acetate fibers and resveratrol loaded cellulose acetate fibers 
Resveratrol yüklü ve yüksüz selüloz asetat liflerinin morfolojileri ESEM ile incelenmiştir. Liflere ait temsili ESEM görüntüleri ve çap histogramları Şekil 2'de verilmiştir. Elde edilen tüm liflerin düzgün yüzeyli olması ve damla içermemesi elektroeğirme prosesinin başarılı bir şekilde gerçekleştirildiğini göstermiştir. Yüklü ve yüksüz liflerin ortalama çapları sırasıyla, $493 \mathrm{~nm}$ ve $478 \mathrm{~nm}$ olarak bulunmuş ve resveratrol ilavesiyle lif çaplarında önemli bir değişim saptanmamıştır.
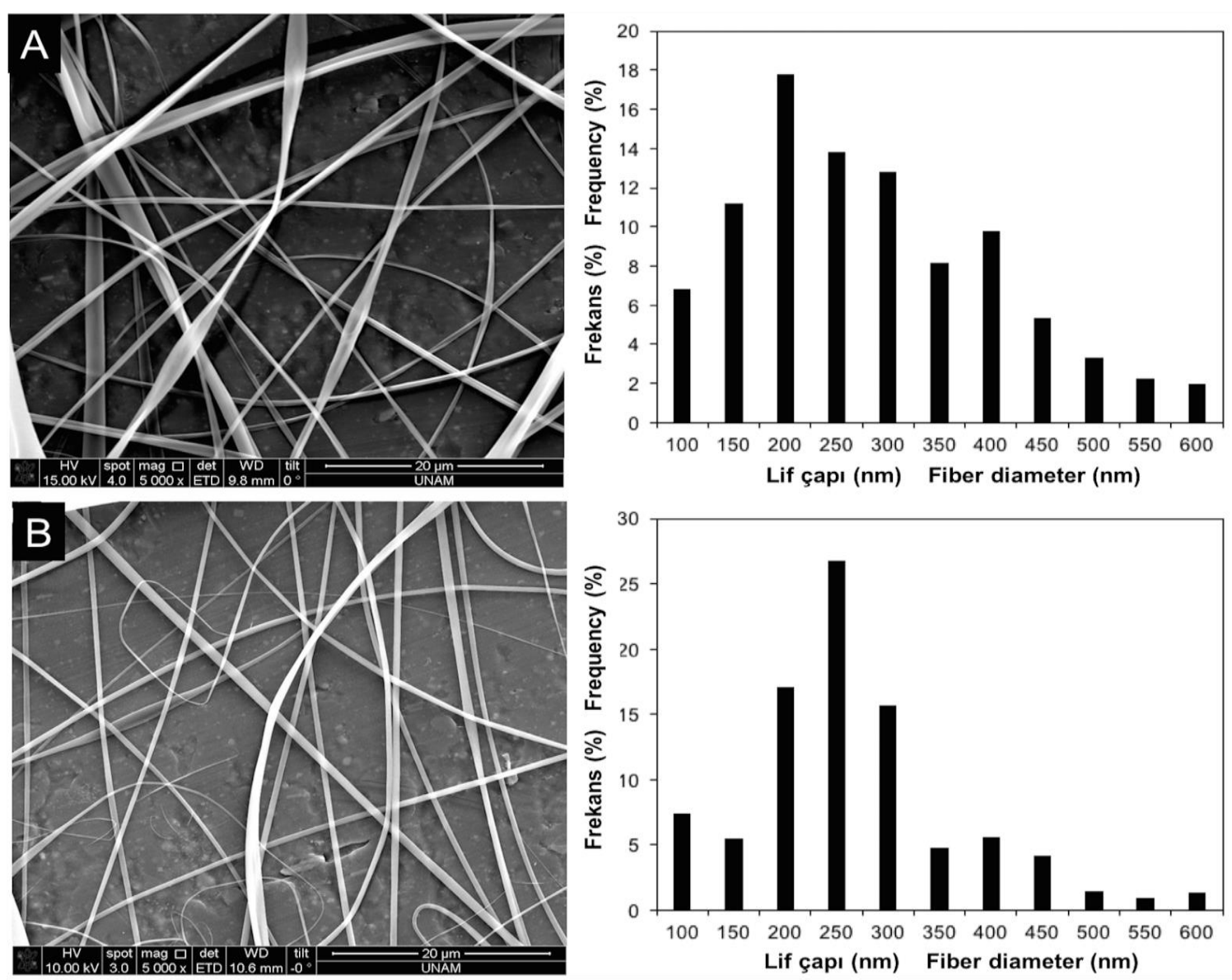

Şekil 2. Resveratrol içermeyen (A) ve resveratrol yüklü (B) selüloz asetat liflerine ait ESEM görüntüleri ve çap histogramlar1

Figure 2. ESEM images and diameter histograms of unloaded (A) and resveratrol loaded (B) cellulose acetate fibers

Elektroeğrilmiş liflerin enkapsülasyon etkinliği ve resveratrolün salınımı

Elektroeğrilmişs selüloz asetat liflerinin resveratrol için enkapsülasyon etkinliğinin belirlenmesi amacıyla lifler tampon çözelti içerisine alınmış ve liflere yüklenen resveratrol miktarından tampon çözeltisine geçen resveratrol miktarının çıkarılması ile enkapsülasyon miktarı belirlenmiştir. Polimer ağırlığının \%.1.5’i kadar yüklenen resveratrol için enkapsülasyon etkinliği \%94.5 \pm 0.6 olarak bulunmuştur. Elde edilen yüksek enkapsülasyon etkinliğinin selüloz asetatın tampon çözeltisindeki düşük çözünürlügünden kaynaklandığı düşünülmektedir (Jyothi vd., 2010).

Tampon çözelti içerisinde liflerden salınan resveratrol miktarı $310 \mathrm{~nm}$ dalgaboyunda absorbans ölçümü ile belirlenmiştir. Selüloz asetat liflerinden resveratrolün salınım profili Şekil 3'te gösterilmektedir. Resveratrol başlangıçta çok hızlı bir salınım göstermiş ve 1 saat sonunda liflerdeki resveratrolün \%7'si salınmıştır. Başlangıçtaki bu 
ani salınımın lif yapılarının yüzeyinde yer alan veya yüzeye yakın moleküllerin hızlı bir şekilde çözeltiye geçmesinden kaynaklandığ düşünülmektedir. Başlangıçtaki ani salınım sonrasinda resveratrol kademeli bir salınım göstermiş, 20. saatten sonra salınan miktar sabit değere ulaşmıştır. 36 saatin sonunda liflere yüklenen resveratrolün \%11’i salınmıştır. Selüloz asetat liflerinin sulu çözeltilerdeki düşük çözünürlüğü ve porsuz bir yapıya sahip olması, bu liflere yüklenen bileşiklerin kısmi salınımına neden olmaktadır (Yan vd., 2014). Bu durum kontrollü salınım sistemleri için tasarlanan liflerde büyük bir sorun olarak karşılanırken, gıdalara katılacak olan biyoaktif bileşiklerin enkapsülasyonu için önemli bir avantaj sağlamaktadır. Böylece gidaların depolama süresi boyunca bileşiklerin korunması sağlanabilmektedir. Ancak bu durumda enkapsülasyon sisteminin tüketim sonrasında sindirim sistemindeki salınım özellikleri büyük önem kazanmakta ve sindirim sonrasinda da bileşiğin tamamen salınmaması olumsuz bir durum olarak değerlendirilmektedir (Kiatyongchai vd., 2014). Bu nedenle, sulu ortamdaki salınım özellikleri incelendiğinde, selüloz asetat lifleri resveratrolün enkapsülasyonu için umut vadetse de, sindirim sistemindeki salınım özellikleri de mutlaka incelenmelidir.

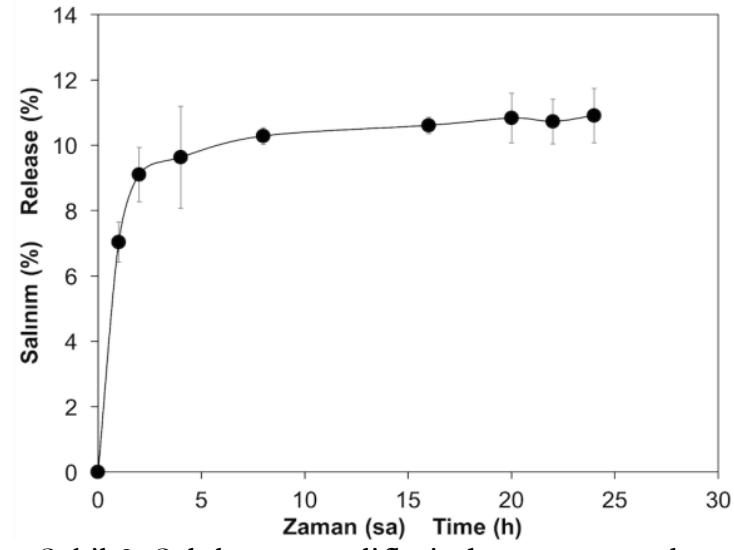

Şekil 3. Selüloz asetat liflerinden resveratrolün salınım profili

Figure 3. Release profile of resveratrol from cellulose acetate fibers

\section{Antioksidan aktivite}

Serbest resveratrol, resveratrol yüklü lifler ve yüksüz lifler iki farklı sıcaklıkta $\left(4^{\circ} \mathrm{C}\right.$ ve $\left.25^{\circ} \mathrm{C}\right) 14$ gün boyunca depolanmış ve belli zaman aralıklarında antioksidan aktiviteleri DPPH analizi ile belirlenmiştir (Şekil 4). Resveratrol içermeyen selüloz asetat lifleri antioksidan aktivite göstermemişlerdir. Depolamanın başlangıcında serbest resveratrolün ve resveratrol yüklü liflerin benzer antioksidan aktivite göstermeleri resveratrolün antioksidan özelliklerinin elektroeğirme prosesinden etkilenmediğini ortaya koymuştur. Depolama sıcaklığının $4^{\circ} \mathrm{C}$ olduğu durumda (Şekil 4a), ilk 3 gün boyunca serbest resveratrolün ve resveratrol yüklü liflerin antioksidan aktivitelerinde benzer düşüş görülmüştür. Sonrasında, serbest resveratrolün antioksidan aktivitesinde hızlı bir düşüş gözlenirken enkapsüle resveratrolün antioksidan aktivitesinde daha yavaş bir azalış meydana gelmiştir. Depolama süresinin sonunda, serbest resveratrol antioksidan aktivitesi \%51'e düşerken, resveratrol yüklü liflerin aktivitesi \%70'e düşmüştür. Depolama sicaklığının $25^{\circ} \mathrm{C}$ olduğu durumda da benzer bir eğilim görülmüş (Șekil 4b) ve depolama süresinin sonunda, serbest resveratrol antioksidan aktivitesi $\% 40$ ve resveratrol yüklü liflerin aktivitesi $\% 59$ olarak belirlenmiştir.

Son yıllarda elektroeğirme prosesi farklı biyoaktif bileşiklerin liflere enkapsülasyonu amaciyla sıkça kullanılmaya başlanmışır. Bu çalışmada, elektroeğirme ile antioksidan aktiviteye sahip resveratrolün düzgün ve tekdüze selüloz asetat liflere enkapsülasyonu gerçekleştirilmiştir. Resveratrolün liflerden salınım özellikleri incelendiğinde ise bileşiğin salınımının 20 saatten sonra durduğu ve başlangiçta yüklenen resveratrolün \%89'unun lif içinde kaldığ1 görülmüştür. Son olarak, üretilen liflerin resveratrolün enkapsülasyonu için kullanılabilirliğini ortaya koymak için iki farklı sicaklıkta depolama esnasındaki antioksidan aktivitedeki değişim incelenmiştir. Sonuçlar incelendiğinde serbest resveratrolle kıyaslandığında, elektroeğrilmiş lifler ile enkapsülasyonun resveratrolün antioksidan kapasitesini arttırdığ1 görülmüştür. Çalışmanın sonucunda, üretilen selüloz asetat liflerinin g1da endüstrisinde antioksidan maddelerin enkapsülasyonunda etkin bir şekilde kullanılabileceği ortaya konmuştur. 

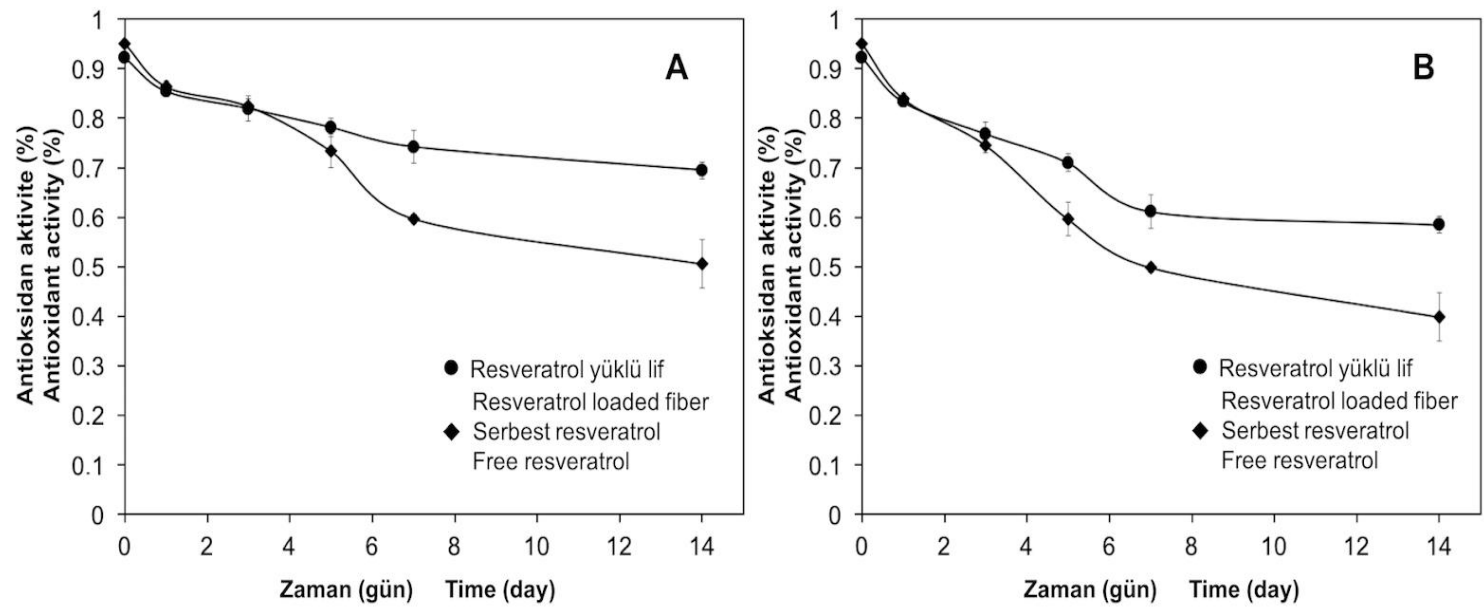

Şekil 4. Serbest resveratrol ve resveratrol yüklü selüloz asetat liflerinin $4^{\circ} \mathrm{C}$ (A) ve $25^{\circ} \mathrm{C}$ 'de (B) depolama sirasındaki antioksidan aktiviteleri

Figure 4. Antioxidant activity of free resveratrol and resveratrol loaded cellulose acetate fibers during the storage at $4{ }^{\circ} \mathrm{C}$ (A) and $25^{\circ} \mathrm{C}$ (B)

\section{KAYNAKLAR}

Aceituno-Medina, M., Mendoza, S., Lagaron, J.M., Lopez-Rubio, A. (2015). Photoprotection of folic acid upon encapsulation in food-grade amaranth (Amaranthus bypochondriacus L.) protein isolate-Pullulan electrospun fibers. Lebensm-Wiss Technol 62: 970-975, doi: 10.1016/j.lwt. 2015.02.025.

Al-Attar, T., Madihally, S.V. (2018). Influence of controlled release of resveratrol from electrospun fibers in combination with siRNA on leukemia cells. Eur J Pharm Sci 123: 173-183, doi: 10.1016/j.ejps.2018.07.043.

Alves, N.E.G., Valdés, S.T., Silveira, C.M.M., Martino, H.S.D.D., Milagro, F.I., Moreno-Aliaga, M.J., Ribeiro, S.M.R. (2012). Studies on mechanistic role of natural bioactive compounds in the management of obesity an overview. Open Nutracenticals J 5: 193-206, doi: http://dx.doi.org/10.2174/18763960012050101 93.

Aytac, Z., Yildiz, Z.I., Kayaci-Senirmak, F., Tekinay, T., Uyar, T. (2017). Electrospinning of cyclodextrin/linalool-inclusion complex nanofibers: Fast-dissolving nanofibrous web with prolonged release and antibacterial activity. Food Chem 231: 192-201, doi: 10.1016/j.foodchem. 2017.03.113
Chantarodsakun, T., Vongsetskul, T., Jangpatarapongsa, K., Tuchinda, P., Uamsiri, S., Bamrungcharoen, C., Kumkate, S., Opaprakasit, P., Tangboriboonrat, P. (2014). [6]-Gingerolloaded cellulose acetate electrospun fibers as a topical carrier for controlled release. Polym Bull 71: 3163-3176, doi: 10.1007/s00289-014-1243-x.

Davidov-Pardo, G., McClements, D.J. (2014). Resveratrol encapsulation: Designing delivery systems to overcome solubility, stability and bioavailability issues. Trends Food Sci Tech 38: 88e103, 10.1016/j.tifs.2014.05.003.

Ghorani, B., Tucker, N. (2015). Fundamentals of electrospinning as a novel delivery vehicle for bioactive compounds in food nanotechnology. Food Hydrocoll 51: 227-240, doi: 10.1016/j.foodhyd.2015.05.024

Han, S.O., Youk, J.H., Min, K.D., Kang, Y.O., Park, W.H. (2008). Electrospinning of cellulose acetate nanofibers using a mixed solvent of acetic acid/water: Effects of solvent composition on the fiber diameter. Mater Lett 62: 759-762, doi: 10.1016/j.matlet.2007.06.059

Jyothi, N.V., Prasanna, P.M., Sakarkar, S.N., Prabha, K.S., Ramaiah, P.S., Srawan, G.Y. (2010). Microencapsulation techniques, factors influencing encapsulation efficiency. $J$ 
Microencapsul 27: 187-197, doi: 10.3109/02652040903131301

Keun, S.W., Ho, Y.J., Seung, L.T., Ho, P.W. (2004). Electrospinning of ultrafine cellulose acetate fibers: Studies of a new solvent system and deacetylation of ultrafine cellulose acetate fibers. $J$ Polym Sci Pol Phys 42: 5-11, doi: 10.1002/polb.10668.

Kiatyongchai, T., Wongsasulak, S., Yoovidhya, T. (2014). Coaxial Electrospinning and Release Characteristics of Cellulose Acetate-Gelatin Blend Encapsulating a Model Drug. J Appl Polym Sci 131: 40167, doi: 10.1002/app.40167

Kumpugdee-Vollrath, M., Ibold, Y., Sriamornsak, P. (2012). Solid state characterization of trans resveratrol complexes with different cyclodextrins. JAASP 1(2): 125 -136.

Orallo, F., Alvarez, E., Camina, M., Leiro, J. M., Gomez, E., Fernandez, P. (2002). The possible implication of trans-Resveratrol in the cardioprotective effects of long-term moderate wine consumption. Mol Pharmacol 61: 294-302, doi: 10.1111/j.1749-6632.2010.05843.x

Palsamy, P., Subramanian, S. (2011). Resveratrol protects diabetic kidney by attenuating hyperglycemia-mediated oxidative stress and renal inflammatory cytokines via Nrf2-Keap1 signaling. Biochim Biophys Acta 1812: 719-731, doi: 10.1016/j.bbadis.2011.03.008.

Penalva, R., Esparza, I., Larraneta, E., GonzálezNavarro, C.J., Gamazo, C., Irache, J.M. (2015). Zein-based nanoparticles improve the oral bioavailability of resveratrol and its antiinflammatory effects in a mouse model of endotoxic shock.J Agric Food Chem 63: 5603-5611, doi: 10.1021/jf505694e.

Poornima, B., Korrapati, P.S. (2017). Fabrication of chitosan-polycaprolactone composite nanofibrousscaffold for simultaneous delivery of ferulic acid and resveratrol. Carbobydr Polym 157: 1741-1749, doi: 10.1016/j.carbpol.2016.11.056.

Rauf, A., Imran, M., Suleria, H.A.R., Ahmad, B., Peters, D.G., Mubarak, M.S. (2017). A comprehensive review of the health perspectives of resveratrol. Food Funct 8: 4284-4305, doi:10.1039/c7fo01300k.

Riccitiello, F., De Luise, A., Conte, R., D'Aniello, S., Vittoria, V., Di Salle, A., Calarco, A., Peluso, G. (2018). Effect of resveratrol release kinetic from electrospun

nanofibers on osteoblast and osteoclast

differentiation. Eur Polym J 99: 289-297, doi: 10.1016/j.eurpolymj.2017.12.035

Serpen, A., Capuano, E., Fogliano, V., Gökmen, V. (2007). A New Procedure To Measure the Antioxidant Activity of Insoluble Food Components. J Agric Food Chem 55: 76767681, doi: 10.1021/jf071291z

Suwantong, O., Opanasopit, P., Ruktanonchai, U., Supaphol, P. (2007). Electrospun cellulose acetate fiber mats containing curcumin and release characteristic of the herbal substance. Polymer 48: 7546-7557, doi: 10.1016/j.polymer.2007.11.019

Suwantong, O., Ruktanonchai, U., Supaphol, P. (2008). Electrospun cellulose acetate fiber mats containing asiaticoside or Centella asiatica crude extract and the release characteristics of asiaticoside. Polymer 49: 4239-4247, doi: 10.1016/j.polymer.2008.07.020.

Timmers, S., Konings, E., Bilet, L., Houtkooper, R.H., van de Weijer, T., Goossens, G.H., Hoeks, J., van der Krieken, S., Ryu, D., Kersten, S., Moonen-Kornips, E., Hesselink, M.K., Kunz, I., SchrauwenHinderling, V.B., Blaak, E.E., Auwerx, J., Schrauwen, P. (2011). Calorie restriction-like effects of 30 days of resveratrol supplementation on energy metabolism and metabolic profile in obese humans. Cell Metab 14: 612-622, doi: https://doi.org/10.1016/j.cmet. 2011.10.002.

Vongsetskul, T., Phurayar, P., Chutimasakul, T., Tuchinda, P., Uamsiri, S., Kumkate, S., Pearngam, P., Jitpibull, J., Samphaongern, C., Tangboriboonrat, P. (2016). Acanthus ebracteatus Vahl. extract-loaded cellulose acetate ultrafine fibers as a topical carrier for controlledrelease applications. Polym Bull 73: 3319-3331, doi: 10.1007/s00289-016-1658-7 
Yan, J., White, K., Yu, D.G., Zhao, X.Y. (2014). Sustained-release multiple-component cellulose acetate nanofibers fabricated using a modified coaxial electrospinning process. J Mater Sci 49: 538-547, doi: 10.1007/s10853-013-7733-7.
Zupančič, Š., Baumgartner, S., Lavrič, Z., Petelin, M., Kristl, J. (2015). Local delivery of resveratrol using polycaprolactone nanofibers for treatment of periodontal disease. J Drug Deliv Sci Tec 30: 408-416, doi: 10.1016/j.jddst.2015.07.009. 